\title{
INTERMEZZO: O XAMÃ E O MÉDICO, UMA ANÁLISE SOBRE DOENÇA E
} CURA

Marcelly Olívia Fernandes Amorim (UFU/FAPEMIG - marcellyolivia@yahoo.com.br).

Érika de Freitas Arvelos (UFU/CAPES - erikafreitasarvelos@ gmail.com).

RESUMO: O PRESENTE ARTIGO ABORDA OS PONTOS DE INTERSECÇÕES ENTRE O PENSAMENTO OCIDENTAL E A CONCEPÇÃO DOS POVOS ORIGINÁRIOS EM RELAÇÃO AO SIGNIFICADO QUE ATRIBUEM À DOENÇA E À CURA. À VISTA DISSO, NOSSO OBJETIVO CENTRAL É ESTABELECER RELAÇÕES ENTRE ESSES DOIS SABERES SINALIZANDO SUAS DISSONÂNCIAS E SIMETRIAS. POR SE TRATAR DE PRÁTICAS QUE ENVOLVEM UMA MULTIPLICIDADE DE QUESTÕES E AGENTES, FOI NECESSÁRIO UM RECORTE, E NESTA PESQUISA NOSSA ANÁLISE SE REFERE À FIGURA DO XAMÃ NA PRÁTICA DE CURA XAMÂNICA, E A FIGURA DO MÉDICO NAS SOCIEDADES OCIDENTAIS. PARA TAL EMPENHO ANALÍTICO NOSSO REFERENCIAL SE VOLTA AO CABEDAL TEÓRICO DA ANTROPOLOGIA, HISTÓRIA, FILOSOFIA E LINGUÍSTICA. A PESQUISA ROMPE COM QUALQUER PERSPECTIVA DE UMA HIERARQUIA EPISTEMOLÓGICA ENTRE ESSES DOIS SABERES (XAMANISMO E MEDICINA OCIDENTAL) TENDO COMO PANO DE FUNDO OS DILEMAS ÉTICOS, CULTURAIS, HISTÓRICOS, SOCIAIS E POLÍTICOS INERENTES A CONCEPÇÕES ONTOLÓGICAS DE CONHECIMENTOS DISTINTOS QUE ACOMPANHAM O PROCESSO HISTÓRICO DE FORMAÇÃO DESSAS PRÁTICAS.

PALAVRAS-CHAVES: XAMANISMO; MEDICINA OCIDENTAL; RIZOMA.

\section{INTERMEZZO: THE SHAMAN AND THE DOCTOR, AN ANALYSIS OF DISEASE AND HEALING}

\begin{abstract}
THE ARTICLE IS AN APPROACH ABOUT THE POINTS OF INTERSECTION BETWEEN WESTERN THOUGHT AND THE CONCEPTION OF ORIGINATING PEOPLES ABOUT THE MEANING ATTRIBUTED TO DISEASE AND HEALING. IN VIEW OF THIS, OUR CENTRAL OBJETIVE IS TO ESTABLISH RELATIONS BETWEEN THESE TWO KNOWLEDGE, SIGNALING THEIR DISSONANCES AND SYMMETRIES. IT WAS NECESSARY CUT OUT BECAUSE IT POINT PRACTICES THAT CONCERN A MULTIPLICITY OF ISSUES AND AGENTS, AND IN THIS RESEARCH THE ANALYSIS REFERS TO THE FIGURE OF THE SHAMAN IN THE PRACTICE OF SHAMANIC HEALING, AND THE FIGURE OF THE DOCTOR IN WESTERN SOCIETIES. FOR SUCH AN ANALYTICAL COMMITMENT, OUR FRAME OF REFERENCE IS BASED ON THE THEORETICAL FRAMEWORK OF ANTHROPOLOGY, HISTORY, PHILOSOPHY AND LINGUISTICS. THE RESEARCH BREAKS WITH ANY PERSPECTIVE OF AN EPISTEMIC HIERARCHY BETWEEN THESE TWO KNOWLEDGES (SHAMANISM AND WESTERN MEDICINE) SHOWING THE ETHICAL, CULTURAL, HISTORICAL, SOCIAL AND POLITICAL DILEMMAS INTRISIC TO ONTOLOGICAL CONCEPTIONS OF DISTINCT KNOWLEDGE THAT ACCOMPANY THE HISTORICAL PROCESS OF FORMATION OF THESE PRACTICES.
\end{abstract}

KEYWORDS: SHAMANISM; WESTERN MEDICINE; RHIZOME 


\title{
INTERMEZZO: EL SHAMAN Y EL MÉDICO, UN ANÁLISIS SOBRE LA ENFERMEDAD Y LA CURA
}

\begin{abstract}
RESUMEN: EL PRESENTE ARTÍCULO ABORDA LOS PUNTOS DE INTERSECCIÓN ENTRE EL PENSAMIENTO Y LA CONCEPCIÓN DE LOS PUEBLOS ORIGINALES EN RELACIÓN CON EL SIGNIFICADO QUE SE ATRIBUYE A ENFERMEDAD Y À CURA. A VISTA DE ESO, NUESTRO OBJETIVO CENTRAL É ESTABLECER RELACIONES ENTRE ESES DOS SABERES. SE TRATA DE PRÁCTICAS DE DESARROLLO DE LA MULTIPLICIDAD DE PREGUNTAS Y DE LOS AGENTES. EN LA INVESTIGACIONES UTILIZAMOS LA TEORÍA DE LA ANTROPOLOGÍA, LA HISTORIA, LA FILOSOFÍA Y LA LINGÜÍSTICA. LA PESQUISA DESATIENDE CON CUALQUIER PERSPECTIVA DE UNA JERARQUÍA EPISTEMOLÓGICO ENTRE ESTOS DOS CONOCIMIENTOS (CHAMANISMO Y MEDICINA OCCIDENTAL) PORQUE TIENE EM CUENTA LOS DILEMAS ÉTNICOS, CULTURALES, HISTÓRICOS Y POLÍTICOS INHERENTES A LA CONCEPCIÓN ONTOLÓGICA DEL CONOCIMIENTO Y DEL PROCESO HISTÓRICO DE FORMACIÓN DE ESAS PRÁCTICAS.
\end{abstract}

PALABRAS-CLAVES: CHAMANISMO; MEDICINA OCCIDENTAL; RIZOMA.

Um rizoma não cessaria de conectar cadeias semióticas, organizações de poder, ocorrências que remetem às artes, às ciências, às lutas sociais. Uma cadeia semiótica é como um tubérculo que aglomera atos muito diversos, linguísticos, mas também perceptivos, mímicos, gestuais, cogitativos: não existe língua em si, nem universalidade da linguagem, mas um concurso de dialetos, de patoás, de gírias, de línguas especiais. Não existe locutor-auditor ideal, como também não existe comunidade linguística homogênea. - Gilles Deleuze \& Félix Guattari

\section{INTRODUÇÃO}

O presente artigo é o resultado do desenvolvimento de uma pesquisa de base documental e bibliográfica que buscou compreender, a partir dos trabalhos da Antropologia, Linguística e Filosofia pontos de intersecções entre os saberes dos povos originários: o xamanismo e a medicina ocidental ${ }^{1}$. A delimitação do tema explicitou o que é o sistema xamânico de cura com ênfase na figura do xamã e o entendimento que se tem sobre doença e cura. Posterior a esse levantamento histórico-bibliográfico, apresentamos concepções sobre a cura e a doença na sociedade ocidental, em torno das práticas agenciadas pelo médico. Nesse sentido, surge o interesse em expor e relacionar suas classificações e significações sobre doença e cura.

Neste trabalho, a articulação entre esses saberes e práticas foi compreendida para além da ideia binária que divide saberes tradicionais dos povos originários e a medicina

\footnotetext{
${ }^{1} \mathrm{O}$ termo medicina ocidental foi usado como sinônimo de biomedicina, contemplando a medicina clínica fundada nos princípios das ciências naturais como biologia, bioquímica, biofísica etc. Sabemos que existem outras formas de se fazer medicina, que nenhuma sociedade pratica apenas um tipo de medicina, mas sempre há uma prática que predomina.
} 
ocidental, só assim, com o rompimento dessa premissa binária foi possível transitar e traduzir os sentidos e simetrias significativos do que se entende por doença, tratamento e cura em sociedades de cosmologias distintas.

Voltamo-nos à abordagem da antropologia simétrica, que nos mostra uma associação entre fatores humanos e não humanos e os respectivos papéis e efeitos que cada um produz no processo saúde/doença, tratamento/cura. Segundo a teoria ator rede (ANT), o ator é determinado a partir do papel que desempenha, conforme a sua atuação e como isso reflete na sua rede, portanto, pode-se dizer que pessoas, animais, coisas, objetos e instituições podem ser um ator. Visto que, a antropologia simétrica nos permite apresentar os elementos relacionados às práticas de tratamento e cura de doença como providos de poder de agenciamento, nas duas configurações de conhecimento (médico e xamânico), como exames laboratoriais, remédios, seres espirituais, plantas, igualmente fundamentais para o processo tratamento-cura. Além de nos levar à "construção de relações menos desiguais entre os dois sistemas de conhecimento e seus pressupostos ontológicos" (SILVEIRA 2012:14).

Antes de delimitar sobre os conhecimentos dos povos originários e os saberes ocidentais foi necessário primeiramente compreender as concepções dessas culturas, para depois adentrar no universo significativo da saúde e da doença nas seções subsequentes. Para compreensão mais precisa dessa questão, Geertz (1989) nos guia em uma análise semiótica do entendimento do que são os padrões culturais, nos quais nos baseamos para realizar a tradução desses saberes:

Os padrões culturais são "modelos", de que eles são conjuntos de símbolos cujas relações uns com os outros "modelam" as relações entre as entidades, os processos ou o que quer que seja nos sistemas físico, orgânico, social ou psicológico "fazendo paralelos", "imitando" ou "estimulando-os". Entretanto, o termo "modelo" tem dois sentidos — um sentido "de" e um sentido "para" — e, embora estes sejam dois aspectos de um mesmo conceito básico, vale a pena diferenciá-los para propósitos analíticos. No primeiro caso, o que se enfatiza é a manipulação das estruturas simbólicas de forma a colocá-las, mais ou menos próximas, num paralelo com o sistema não-simbólico preestabelecido, como ocorre quando apreendemos como funciona um dique desenvolvendo uma teoria de hidráulica ou construindo um mapa de fluxo. A teoria ou o mapa modela as relações físicas de tal maneira - isto é, expressando a sua estrutura numa forma sinóptica - que poderão ser apreendidas; trata-se de um modelo da "realidade". No segundo caso, o que se enfatiza é a manipulação dos sistemas não-simbólicos, em termos das relações expressas no simbólico, como quando construímos um dique de acordo com as especificações contidas em uma teoria hidráulica ou as conclusões tiradas de um mapa de fluxo. Aqui, a 
teoria é único modelo sob cuja orientação são organizadas as relações físicas é um modelo para a "realidade". A situação não é muito diferente nos sistemas psicológico e social e nos modelos culturais aos quais não nos referiríamos, entretanto, como "teorias", mas como "doutrinas", "melodias" ou "ritos". Diferente dos genes e outras fontes de informação não-simbólicas, os quais são apenas modelos para, não modelos de, os padrões culturais têm um aspecto duplo, intrínseco - eles dão significado, isto é, uma forma conceptual objetiva, à realidade social e psicológica, modelando-se em conformidade a ela e ao mesmo tempo modelando-a a eles mesmos ( GEERTZ 1989:69).

Essa citação nos leva a interpretar que os padrões culturais dos costumes sociais se dão mediante processos de constante mudança, isto é, são mutáveis. Por essa razão, torna-se necessário acessar, observar e compreender os signos, os significados e os significantes que estão relacionados a perspectivas distintas do que é e o que se entende por saúde e doença para cosmologias diferentes.

\section{ONTOLOGIA XAMÂNICA: XAMÃ, XAMANISMO, DOENÇA E CURA}

É a pura inauguração de um outro universo. Que vai corromper, irromper, irrigar e recompor a natureza. -Manoel de Barros

Nesta sessão, a princípio, apresentamos os conceitos básicos sobre o Xamanismo dos povos originários. Levando em consideração uma gama de teorias, certamente foi feito um recorte, e este trabalho usará as acepções de E. Jean Matteson Langdon, Eduardo Viveiros de Castro, Claude Lévi Strauss, Stanley Krippner e Métraux, para que assim possamos identificar, dada a complexidade do tema, a definição do Xamanismo e seu sistema de cura.

Analisando especificamente a concepção do termo Xamanismo e suas características, começaremos identificando a figura central e elementar que é a do xamã. Os Xamãs são considerados os primeiros curadores da humanidade, segundo Stanley Krippner (2007). “A própria palavra xamã vem da língua siberiana tungue, e indica o mediador entre o mundo humano e o mundo dos espíritos" (LANGDON 1996:12). 
Os primeiros relatos sobre xamãs aparecem no século passado, e foram escritos por exploradores, naturalistas e viajantes. Para eles, os xamãs eram figuras estranhas e exóticas que apresentavam comportamentos incomuns. (LANGDON:1996) Segundo Métraux (1967), conforme citado por Langdon (1996:13), “fenômenos parecidos seriam também descritos em outras culturas, e a palavra xamã tornou-se universal para indicar tais pessoas e suas atividades, independentemente de sua localização geográfica”.

Conforme os trabalhos de Stanley Krippner: "Os xamãs foram os primeiros psicoterapeutas, primeiros médicos, primeiros mágicos, primeiros artistas performáticos, primeiros contadores de histórias e até mesmo os primeiros previsores do tempo da humanidade (RYAN, apud, KRIPPNER 1999:8)"

O Xamã detém o "poder" de acessar espaços e tempos cosmológicos distintos, como por exemplo, o mundo espiritual e material, das coisas, pessoas e animais, pois domina a habilidade de projetar o espírito e ter contatos com estes outros que transcendem o espaço-tempo da matéria (corpo). De acordo com Langdon:

[...] O xamã interage com estas energias através da experiência extática através dos sonhos, ou dos transes induzidos por substâncias ou outras técnicas, servindo como mediador entre o domínio humano e extra-humano. As fontes dos poderes do xamã são as fontes da própria cultura, e o conhecimento que ele adquire é o conteúdo da cultura. Seu papel como mediador estende-se também ao domínio sociológico, onde ele desempenha um papel tanto importante na cura, quanto nas atividades econômicas e políticas e em outras atividades sociais. (LANGDON 1996:29)

Todas as suas intermediações, segundo Langdon (1996) estão diretamente ligadas ao êxtase, transe em novos estados de consciência, dança, sonhos, entre outros. Neste sentido:

"mente e corpo são vistos como uma unidade e por isso não há divisão rígida entre doenças físicas ou mentais" [...] "dor e outros sintomas são vistos como fontes de informação que podem ser utilizadas no diagnóstico, da mesma forma que os sonhos do cliente, sua aura, campos de energia e eventos incomuns da vida" (KRIPPNER 2007:21).

$\mathrm{Na}$ cosmologia dos povos originários, a doença é explicada como algo provocado por seres vivos, não vivos, isto é, os espíritos, e pela reação da natureza. Para tal, existe uma outra noção de corporalidade (outros significados), que vai além do entendimento ocidental, que na maioria das práticas é baseado apenas em pressupostos biológicos. Em A Construção da Pessoa nas Sociedades Indígenas Brasileiras, Seeger, 
Da Matta, Viveiros de Castro (1979) colocam que “a fabricação, decoração, transformação e destruição dos corpos dos ameríndios são temas em torno dos quais giram as mitologias, a vida cerimonial e a organização social" (SEEGER, DA MATTA, VIVEIROS DE CASTRO 1979:12). Para os autores, de acordo com o perspectivismo ameríndio e multinaturalismo, o que define os diferentes tipos de gente são os seus corpos, que são construídos por meio dos agenciamentos míticos, e não suas culturas. Portanto, para os povos originários não existe doença causada naturalmente, relacionada com o biológico ou devido a uma herança genética; ela é sempre adquirida, ou seja, a pessoa atrai a doença para si, por meio das suas condutas morais e espirituais.

Os diversos grupos dos povos originários no Brasil, de maneira peculiar, pensam a saúde como algo natural, pois configura a própria vida, um presente da natureza e cujo cuidado depende de uma vigilância permanente contra os seres vivos (pessoas e animais que possam provocar uma doença) e não "vivos" (espíritos). A doença, portanto, é o resultado desta vigilância interna que envolve todos os seres de natureza e habitantes de outro espaço- tempo (os espíritos).

Desta forma, a saúde não é constituída como algo independente ou alheio, mas está relacionada aos fatores mais amplos da coletividade, da forma de organização social, das conexões com a natureza, isto é, da cosmologia. Esta análise, no que lhe concerne, exige um entendimento daquilo que os povos originários compreendem por natureza, que não é essencialmente dualista, onde seres naturais e sobrenaturais são os responsáveis pela formação de um todo, mas trata-se de vários agentes que se comunicam. Assim, todos os seres (animais, plantas) são humanos em potência, a partir de relações dadas em um mesmo momento (VIVEIROS DE CASTRO 2002:135).

O conceito de saúde pela perspectiva dos povos originários no Brasil ${ }^{2}$ está ligada à concepção de viver em harmonia e equilíbrio com a natureza, motivo pelo qual o território é para eles algo sagrado e vital e a doença (mal) surge quando essa harmonia é transgredida. Desta forma, os conhecimentos tradicionais dos povos originários a respeito da saúde assentam-se em uma abordagem holística, cujo princípio é a harmonia de indivíduos, famílias e comunidades com o universo que os envolvem.

\footnotetext{
${ }^{2}$ Usamos de forma genérica, pois a lógica do pensamento ameríndio é a mesma (permite uma diversidade de visões de mundo), mas existem diversos grupos indígenas no Brasil e cada um apresenta suas especificidades ao conceituar e tratar a doença.
} 
O conhecimento e os valores indígenas são pautados na diversidade de visões de mundo e de homem, na forma como é organizada a vida social, os conhecimentos e os valores que são transmitidos pela tradição oral e pela experiência empírica. Por isso que o procedimento de cura irá variar, entre eles podemos citar, por exemplo o uso de plantas, cantigas, orações, rituais e purificações. À vista disso, notamos que o entendimento de doença é amplo na perspectiva xamânica, assim, os tratamentos das doenças também variam e dependem do diagnóstico que está diretamente ligado às tradições culturais:

Se um membro da comunidade parece estar sofrendo de "perda da alma", um xamã vai procurar pela alma do cliente, restituindo-a antes que a pessoa sucumba a uma condição terminal. O diagnóstico determina se a alma foi roubada ou extraviada do corpo. $\mathrm{O}$ tratamento é dirigido para a recuperação da alma por intermédio do "apanha-almas" (soul-catching) ou de um procedimento semelhante. (KRIPPNER 2007:20)

O responsável por esse processo de cura é o xamã, por conta de suas habilidades, são considerados seres travestis de seu tempo, que nas viagens xamânicas em contato com outros seres de cura $^{3}$, realizam o ritual para curar aqueles que se encontram doentes. O uso das plantas nos xamanismos é um dos principais veículos para a cura de doenças físicas e espirituais. Por fim, é importante destacar que as representações e o papel do xamã variam de uma sociedade para outra.

De certo, indubitavelmente nota-se que o xamanismo é uma política cósmica, ou seja, o xamanismo está ligado a "um modo de agir que implica um modo de conhecer, ou antes, um certo ideal de conhecimento" (VIVEIROS DE CASTRO 2013: 358). Sob os estudos de Viveiros de Castro (2013) podemos partir de uma conceituação das principais características que envolvem esta prática para proceder à análise subsequente:

[...] a atividade xamânica consiste no estabelecimento de correlações ou traduções entre os mundos respectivos de cada espécie natural, com a busca de homologias e equivalências ativas entre os diferentes pontos de vista em confronto." Mas o xamã ele próprio é um "relator" real, não um "correlator"

\footnotetext{
3 “Os Ashaninka [explica Carlito Cataiano] consideram o japiim (Cacicus cela), que nós, Kaxi [i.e. Kaxinawá], chamamos txana, um curador poderoso. Os Ashaninka gostam de fazer suas casas perto dos ninhos do txana, porque quando tomam cipó o espírito do txana vem ajudá-los a curar os doentes; em suas cantorias e mirações do cipó, os pajés Ashaninka, em suas canções do ayahuasca chamam e vêem os espíritos do japiim e do japó; têm ainda muito respeito por esses dois pássaros, que fazem seus ninhos nas proximidades de suas casas; ninguém persegue esses pássaros, tidos como inteligentes, trabalhadores e, sobretudo, bons curadores [...] (CUNHA 1998:15)
} 
formal: é preciso que ele passe de um ponto de vista a outro, que se transforme em animal para que possa transformar o animal em humano e reciprocamente. O xamã utiliza - substância e encama, relaciona e relata as diferenças de potencial inerentes às divergências de perspectivas que constituem o cosmos: seu poder, e os limites de seu poder, derivam dessas diferenças. (VIVEIROS DE CASTRO 2013: 97)

Nota-se em Lévi-Strauss (1975) que existe uma organização de dois pólos, um que é dado pela experiência do Xamã e outro que é o consenso coletivo. Frente a essas teorias, podemos afirmar que o universo xamânico está diretamente ligado a uma metafísica espacial (espiritual), ou seja, está para além da materialidade. O xamanismo, segundo Langdon (1996), estão interligados dentro de uma teia simbólica cultural, por isso que o xamanismo é um complexo cultural e, portanto, específico de um determinado povo.

\section{SOBRE A MEDICINA OCIDENTAL: DOENÇA E CURA}

O novo sistema,observa-se,também é de tipo fractal. Manoela Carneiro da Cunha

Neste momento apresentamos o conceito de doença, por meio das relações sociais, culturais e históricas características da sociedade ocidental, apropriando-nos de teóricos que dispõem de abordagens críticas sobre o conceito de doença, tratamento e cura na perspectiva dos ocidentais, como Barros (2002), Capra (1982), MARTINS et al. (1997), Foucault $(1979,2010)$ e também de Langdon (2010) que nos permite pensar e identificar a construção do conceito sobre doença dentro de um campo de significados específicos desta sociedade.

O conceito ocidental de doença é fortemente trabalhado na biomedicina ${ }^{4}$, e nela é definido como um dano nos sistemas que leva à falha estrutural de órgão vitais dos seres humanos. Segundo Barros (2002) a biomedicina, ao definir o conceito de doença, enfatiza "a doença", tratando o corpo em partes cada vez menores, reduzindo a saúde a um funcionamento mecânico do corpo.

Conforme Capra (1982) a concepção limitada do modelo biomédico de doença, ao argumentar que este consiste num tipo ideal da teoria mecanicista, em que o homem

\footnotetext{
${ }^{4} \mathrm{O}$ termo biomedicina refere-se a medicina clínica fundada nos princípios das ciências naturais como biologia, bioquímica, biofísica etc.
} 
é visto como um corpo-máquina; o médico, como um mecânico; e a doença, o defeito da máquina nos remete a uma construção sociocultural histórica. Esta percepção do homem como máquina é uma construção histórica que aparece com o surgimento do capitalismo.

Para Martins et al (1997) a primeira explicação, dentro dos padrões científicos, foi baseada na teoria dos miasmas. Esta teoria explicava a associação entre o surgimento de epidemias e as condições do ambiente. Os miasmas seriam gases decorrentes da putrefação da matéria orgânica que produziam doenças quando absorvidos pelos seres vivos. Esta teoria dos miasmas não conseguiu explicar por muito tempo o surgimento das doenças, visto que a ciência descobriu os microrganismos (teoria microbiana).

A teoria microbiana propiciou a primeira revolução sanitária, a partir da introdução de pesquisas sobre as relações entre organização social, pobreza e a periodicidade de doenças. De acordo com esta teoria (microbiana), cada doença teria por agente causal um organismo específico, que poderia ser identificado, isolado e ter suas características estudadas. A intervenção para cuidar da doença é baseada numa visão reducionista e mecanicista, em que o médico especialista é o mecânico que tratará da parte do corpo-máquina defeituosa ou do ambiente para o controle das possíveis causas de epidemias.

De acordo com Fundação Oswaldo Cruz, essa visão biomédica e mecanicista da saúde foi rompida em 1958 quando a Organização Mundial da Saúde (OMS) definiu o conceito de saúde como o estado de completo bem-estar físico, mental e social. No sentido de uma visão mais abrangente e dinâmica do processo, no Brasil, a Lei Orgânica de Saúde (LOS), n. 8.080, de 19 de setembro de 1990, avança em relação ao conceito de saúde apresentado pela OMS, pois se apresenta mais ampla, ao colocar em evidência os fatores determinantes e condicionantes do movimento saúde-doença ${ }^{5}$.

Percebe-se então que todo o processo de construção ocidental em torno da saúde e doença ocorreu de modo fundamentalmente racional, estabelecendo razões científicas (saber científico) para a compreensão das enfermidades, estimuladas por instituições,

\footnotetext{
${ }^{5}$ Esta lei regulamenta o Sistema Único de Saúde, e é complementada pela Lei n. 8.142, de dezembro de 1990. Conforme a LOS, a saúde tem como fatores determinantes e condicionantes, entre outros, a alimentação, a moradia, o saneamento básico, o meio ambiente, o trabalho, a renda, a educação, o transporte, o lazer, o acesso a bens e serviços essenciais; os níveis de saúde da população expressam a organização social e econômica do país (Brasil 1990: Art. 3).
} 
como Organização Mundial da Saúde - OMS, os Sistemas de Saúde (pública ou privada), no caso do Brasil o Sistema Único de Saúde - SUS. Desta forma, a sociedade ocidental apresenta uma prática e maneira de pensar peculiares quanto à compreensão da doença, tratamento e cura, da mesma forma que apresentam concepções específicas sobre saúde e procedimentos terapêuticos. Estas especificidades não são resultados de diferenças biológicas, e sim das diferenças ontológicas, historicamente relacionadas aos fatores culturais. Ou seja, o sistema de saúde ocidental evidencia “a dimensão simbólica do entendimento que se tem sobre saúde e inclui os conhecimentos, percepções e cognições utilizadas para definir, classificar, perceber e explicar a doença" (LANGDON 2010: p. 179).

A racionalidade (saber científico) que se desenvolveu em torno da doença, tratamento e cura na sociedade ocidental, só se constituiu mediante o consentimento dos coletivos (médicos, pacientes, instituições) em relação à ideia (científica) que se formou ao longo da história a respeito da doença e da cura. Segundo Foucault (1979), as sociedades constroem "à sua maneira" a sua forma de verdade:

Isto é, os tipos de discurso que ela acolhe e faz funcionar como verdadeiros; os mecanismos e as instâncias que permitem distinguir os enunciados verdadeiros dos falsos, a maneira como se sanciona uns e outros; as técnicas e os procedimentos que são valorizados para a obtenção da verdade; o estatuto daqueles que têm o encargo de dizer o que funciona como verdadeiro (FOUCAULT 1979: 12).

Na perspectiva de Foucault (2010) o poder está relacionado com a produção de saber. Neste caso, a medicina ocidental caracteriza um saber (científico) que se materializa na figura do médico, possuidor do conhecimento (do poder/saber): "O poder produz saber [...], não há relação de poder sem constituição correlata de um campo de saber, nem saber que não suponha e não constitua ao mesmo tempo relações de poder" (FOUCAULT 2010: 30)

A relação médico-paciente é uma interação que envolve confiança por parte do paciente (no conhecimento/saber do médico) e responsabilidade (do médico ao desempenhar suas atividades). Esta relação acontece quando o médico detentor do saber (do conhecimento científico), e logo do poder, orienta o paciente a seguir o recurso médico, a partir de mudanças de hábitos, uso de medicamentos e/ou intervenções cirúrgicas. 
As doenças são diagnosticadas pelo médico em seus consultórios ou hospitais por meio de anamnese ${ }^{6}$, entrevista na qual o médico ou profissional de saúde ajuda o paciente a relembrar todos os fatos que se relacionam com a doença e à pessoa doente, e exames de ressonância magnética, sangue, urina, fezes, raio-x, entre outros, geralmente são feitos em laboratórios de clínica médica ${ }^{7}$, que têm por objetivo evidenciar quaisquer anormalidades. Identificada a causa da doença, na maioria dos casos, o paciente recebe uma prescrição médica (receita médica) com a descrição de medicamentos e orientações sobre o uso dos mesmos e também a respeito das condições de vida que devem ser alteradas (fatores determinantes e condicionantes). Acredita-se que o médico vai identificar a doença e que os medicamentos ${ }^{8}$ irão combater e/ou agir de alguma forma nas células de vírus, bactéria, fungo, ou qualquer que seja o agente causal do adoecimento. Esta relação acontece permeada pelo poder/saber, em que o médico, possuidor do conhecimento estabelece um tratamento e o paciente desempenha. A partir desta terapia, a cura para a doença pode acontecer, assim como a morte do paciente também ${ }^{9}$.

É comum na medicina ocidental a opção por terapias médicas a partir da internação em leitos de hospitais, em que o paciente acometido de alguma doença (neste caso, consideradas mais graves) ficam sob orientação de uma rede de profissionais ligados a saúde. Segundo Foucault (1979), nas sociedades ocidentais “o cuidado do corpo" está orientado "no controle do espaço social, ou seja no controle dos corpos (dos doentes)". Toda a estrutura do hospital (espaço social e corpos doentes) é controlada, por meio da disciplina, horários para banho, para o café da manhã, almoço, lanche, jantar, medicamentos e intervenções cirúrgicas. Desta forma, o paciente confia no

\footnotetext{
${ }^{6}$ Trata-se de uma tarefa essencialmente interpretativa, em que há uma relação reflexiva entre as hipóteses formuladas pelos médicos e os comportamentos e motivações associados ao diagnóstico. Ver: Beato 1994. Práticas de Glosa e Anamnese. In: http://www.scielo.br/pdf/physis/v4n1/03.pdf. (Acessado em 18 de novembro de 2018).

${ }^{7}$ Laboratório de clínica médica é um espaço físico devidamente equipado com instrumentos próprios para a realização de exames (espécie de experimentos e pesquisas com determinado material ou parte do corpo humano para identificar anomalias que causam doenças).

${ }^{8}$ Possuem efeitos comprovados cientificamente. São desenvolvidos em laboratórios químicos, espaços físicos, devidamente equipados com instrumentos, destinados a experimentos que levam à produção de "remédios".

${ }^{9}$ É importante destacarmos que existem doenças tratáveis (que não possuem cura), em que os pacientes permanecem a vida toda (a partir do diagnóstico) em tratamento. Assim como também existem casos em que o paciente se trata, mas não obtém êxito, vindo a falecer. Neste caso o médico considera que o tratamento não conseguiu eliminar os agentes causais (por algum motivo, como mutação deste e ou complicação da própria condição "natural" da doença).
} 
conhecimento científico/médico, em relação ao tratamento da doença e segue internado, recebendo alta, caso apresente melhora. Em alguns casos os medicamentos e intervenções não combatem a doença, que leva a morte do paciente.

Neste trabalho, a articulação entre esses saberes e práticas deve ser compreendida para, sobretudo, pensarmos os sentidos estabelecidos no processo saúde, doença, tratamento e cura em sociedades que apresentam cosmologias diferentes, entre os povos originários, a partir das práticas desenvolvidas pelo xamã e pelo médico na sociedade ocidental, tendo como referência a abordagem da antropologia simétrica, que nos mostra uma associação entre fatores humanos e não humanos (atores, agentes sociais) e os respectivos papéis e efeitos que cada um produz no processo saúde/doença, conforme a sua própria perspectiva.

Para Latour (1994) a modernidade, constituída, ou melhor, criada em torno do pensamento científico, está fundamentada a partir da divisão entre sociedades modernas e sociedades não modernas. Interessa-nos pensarmos neste artigo a sociedade "para além da atual divisão" modernos (sociedade ocidental) e não modernos (não brancos):

"Potencialmente" o mundo moderno é uma invenção total e irreversível que rompe com o passado, da mesma forma que "potencialmente" as Revoluções francesa ou bolchevique são as parteiras de um novo mundo. "Em rede", o mundo moderno, assim como as revoluções, permite apenas prolongamentos de práticas, acelerações na circulação dos conhecimentos, uma extensão das sociedades, um crescimento do número de actantes, numerosos arranjos de antigas crenças (LATOUR 1994:52).

$\mathrm{O}$ autor ainda nos traz o conceito de rede, em que subsistem práticas de ambos os "mundos" (ocidental e não ocidental), mostrando que nunca houve ruptura, "as inovações dos ocidentais (futuro), não são o bastante para construir toda uma história". Deste modo, apresentamos as duas práticas (xamanismo e medicina ocidental) como técnicas que se aproximam ou se afastam, porém coexistindo, buscando maneiras de entender, explicar e tratar as doenças, seja a partir da figura do xamã ou do médico.

\section{PONTOS DE INTERSECÇÕES ENTRE O CONHECIMENTO TRADICIONAL INDÍGENA E O CONHECIMENTO OCIDENTAL}

Então não se perguntará qual o sentido de um acontecimento: o acontecimento éo próprio sentido. $O$ acontecimento pertence essencialmente à linguagem, mantém uma relação essencial com a linguagem; mas a linguagem é o que se diz das coisas. 
Observamos no desenvolvimento do artigo que o entendimento sobre doença e cura para os povos originários no xamanismo, em termos gerais, se diferem da concepção de doença e cura para os não índios (por falta de um termo melhor), pois são entendimentos fabricados a partir de um campo simbólico cultural. Isso se dá por conta de condições específicas nas diferentes concepções, de cunho cultural e significativo, social, econômico, histórico e ambiental. Cada povo originário no Brasil possui um modo próprio de organizar seu campo simbólico para mediar suas relações sociais, políticas e econômicas, seja as internas ao seu grupo ou com outros grupos com os quais mantém contato. Toda organização social de um povo indígena está relacionada a uma concepção de mundo e de vida, isto é, a uma determinada cosmologia organizada e expressa por meio dos mitos, dos ritos e do contato.

As práticas dos povos originários possuem motivações específicas, caracterizadas pela singularidade histórica de suas sociedades. Ou seja, são motivadas por um conjunto de pressupostos e valores, racionais, culturais, simbólicos, éticos, religiosos, políticos e econômicos, tal qual - as práticas sociais dos indivíduos que não estão organizados em sociedades "tradicionais", os não índios, conforme vimos nas primeiras sessões do artigo.

Partindo dessas orientações cosmológicas, pode-se afirmar que os modos de vida dos povos originários, aldeados e não aldeados, e as relações na sociedade ocidental entre médico e paciente, variam de grupo para grupo conforme os tipos de relações de sentido estabelecidas na esfera da cultura, afinal, "a cultura é um conjunto de sistema simbólico" (LÉVI-STRAUS 1975:19). Neste artigo, partimos do pressuposto de que o conceito de cultura é essencialmente semiótico, (GEERTZ:1989). Por isso que essas práticas e entendimento sobre doença e cura se diferem entre si, quando as colocamos em análise, mas é importante chamar atenção de que elas também se relacionam no quesito agenciamento de signos. Isto é, tais práticas se dão por usos de uma língua e linguagem específica na criação de um sistema de crenças.

No que tange o entendimento entre doença, saúde e cura, podemos concluir que são fenômenos que dizem respeito a todas as sociedades humanas. O que acontece é que essas sociedades podem significar de maneiras distintas aquilo que nós denominamos doença, saúde e cura, isto é, na língua-conceito e no entendimento-cosmologia. 
Estar saudável ou doente para os povos originários e para a sociedade ocidental é o resultado do tipo de relação individual e coletiva que se estabelece com as demais pessoas e com a natureza, em um contexto generalista, visto que, existem especificidades de acordo com os diferentes grupos étnicos culturais que também se aplica ao papel do médico e a relação que ele estabelece com a estrutura e saber do não índio.

Podemos analisar as dissonâncias e simetria entre essas duas práticas sobre o prisma da teoria de Deleuze e Guatarri (1995) com o conceito de Rizoma. O conceito de rizoma na Biologia ${ }^{10}$, no que diz respeito aos estudos da botânica, rizoma é um caule modificado, seu crescimento é polimorfo, ou seja, não possui uma direção definida. Ao transpor esse conceito da biologia para análise das relações sociais, o Rizoma passa a representar os encontros imprevistos na modernidade, simbolizando, portanto, uma estrutura de passagens, onde não há começo nem fim, trata-se de um labirinto com múltiplas possibilidades de arranjos. "Pensar, nas coisas, entre as coisas é justamente criar rizomas e não raízes, traçar a linha e não fazer o balanço":

"Um rizoma não começa nem conclui, ele se encontra sempre no meio, entre as coisas, inter-ser, intermezzo. A árvore é filiação, mas o rizoma é aliança, unicamente aliança. A árvore impõe o verbo "ser", mas o rizoma tem como tecido a conjunção "e... e... e..." Há nesta conjunção força suficiente para sacudir e desenraizar o verbo ser. Entre as coisas não designa uma correlação localizável que vai de uma para outra e reciprocamente, mas uma direção perpendicular, um movimento transversal que as carrega uma e outra, riacho sem início nem fim, que rói suas duas margens e adquire velocidade no meio."(DELEUZE \& GUATARRI 1995: 48/49)

Assim é possível perceber movimentos entre o conhecimento tradicional (xamânico) e sociedade ocidental (medicina), em relação às práticas de cura, a partir da associação dos dois conhecimentos, que ocorrem geralmente no contexto da saúde indígena no Brasil e também no campo da etnofarmacologia e nos projetos de farmacognosia ${ }^{11}$.

O Sistema de Saúde Indígena no Brasil tem por objetivo estabelecer ações de prevenções, promoções, proteção e recuperação da saúde dos povos originários, levando

${ }^{10}$ Rizoma: caule horizontal, mais ou menos subterrâneo, portando folhas escamiformes; geralmente chamado de estolão quando acima da superfície do solo e com entrenós longos (JUDD 2009: 55).

${ }^{11} \mathrm{~A}$ farmacognosia é a parte da farmacologia que trata das drogas ou substâncias medicinais em seu estado natural, antes de serem manipuladas. In: http://www.sbfgnosia.org.br/farmacognosia.html (Acessado dia 9 de dezembro de 2018). 
em consideração as concepções, valores e formas peculiares de conceber a saúde e a doença características de cada um. Historicamente, as políticas de assistência à saúde dos povos originários estiveram relacionadas à política indigenista e tinham como objetivo promover a integração do índio na sociedade nacional. De acordo com Luiza Garnelo (2012) o Serviço de Proteção ao Índio (SPI) criado em 1910 deveria, segundo um conjunto específico de obrigações, estimular a vigência de ações educacionais, decidir sobre os direitos fundiários, proteger os conhecimentos tradicionais e fortalecer o desenvolvimento econômico, entretanto, a tutela jurídica do órgão perante as manifestações das comunidades, o caráter positivista e assimilacionista das ações e a incoerência das práticas, impediria que esses objetivos fossem minimamente alcançados. O órgão pretendia, segundo a web site da Fundação Nacional do Índio (FUNAI), transformar o indígena em um trabalhador nacional. Em 1967 durante o regime militar, a Fundação Nacional do Índio substituiu as funções do Serviço de Proteção ao Índio, mas a tutela jurídica do Estado permaneceu e só seria eliminada na Constituição de 1988. Em 1990 as políticas de assistência à saúde, ainda a cargo da FUNAI são transferidas para o Sistema Único de Saúde (SUS), enquanto subsistema.

Após as mudanças setoriais de implementação da política de assistência de saúde por meio da promulgação da Lei Arouca ( ${ }^{\circ}$ 8.080/99), a Fundação Nacional de Saúde (FUNASA) se tornaria a agência responsável pela execução das políticas de saúde indígena. $\mathrm{O}$ modelo implementado pelo governo federal se caracteriza pela disposição hierárquica das instituições, subdivididas de acordo com os parâmetros da burocracia: critérios técnicos da administração pública, regionalização do atendimento e níveis de complexidade dos cuidados médicos. O Sistema de Saúde Indígena dispõe de Casas de saúde indígena, que ficam localizadas nos municípios e recebem os índios das aldeias e dos polos-base para receber tratamento de saúde na cidade. De acordo com Garnelo (2012) essas casas funcionariam como albergues e "sua principal atribuição é o apoio ao paciente indígena em trânsito, para exames ou tratamento, substituindo o suporte familiar ou social com que os indígenas não contam quando se deslocam para o espaço urbano" (GARNELO 2012:30). As Casas de Saúde do Índio funcionariam como uma ponte entre o índio e o espaço urbano (cidade), unindo uma vasta rede de instituições, tais como a FUNAI, ONGS, Ministério Público, Ministério da Saúde, administração pública regional, Agente de Saúde Indígena (AIS), Agente Indígena de Saneamento 
(AISAN), Distrito Sanitário Especial Indígena (DSEI), Fundação Nacional de Saúde (FUNASA), técnico em saúde bucal, médico, enfermeiro, equipes administrativas, responsáveis pela cozinha, entre outros.

Neste contexto, temos fluxos nem sempre simétricos entre as duas práticas de conhecimento, reflexo da visão ocidental colonialista ${ }^{12}$ em relação ao saber científico, gerando ações impositivas no que se refere aos tratamentos médico que não consideram as práticas tradicionais. Em sua tese de doutorado, "Cotidiano, saúde e política: uma etnografia dos profissionais da saúde indígena", Maria Cristina Dias da Silva ${ }^{13}$ verificou que a maior parte dos indígenas considera os profissionais de saúde "insensíveis" às diferenças culturais entre eles, relatando descaso pelas crenças e tradições nos postos de atendimento médico em que recebiam tratamento (SILVA 2010:2).

A autora verificou ainda que a comunidade indígena "projetava expectativas" sobre os profissionais da saúde em torno da promoção de "atenção diferenciada", que nem sempre eram correspondidas, devido as relações de poder (saber), que se estabeleciam entre profissionais da saúde e povos originários. Visto que os profissionais de saúde se configuravam como autoridades médicas privilegiadas/respeitadas devido a obtenção de maior conhecimento, que acarreta na proposição (imposição) do melhor tratamento médico, por exemplo.

Ainda que se admita a existência legítima de outra forma de compreender, viver e explicar doenças e infortúnios, a perspectiva hierárquica assumida pelo médico (ou enfermeiro, técnico de enfermagem, nutricionistas, fisioterapeutas), em relação ao paciente decorre de um longo histórico de luta política pela construção da autoridade médica (no sentido amplo) e que, no caso da saúde pública, ainda pode ser associada a uma autoridade pública, isto é, governamental. Essa forma de autoridade pública, historicamente construída, como um poder-saber (Foucault) deve ser analisada em face de um contexto de desmembramento das atribuições sobre a gestão da saúde dos povos indígenas no Brasil (SILVA 2010:6).

\footnotetext{
12 Mignolo (2003) trabalha com a proposta dos paradigmas outros, ligados a outras conjecturas políticas, éticas, econômicas e epistemológicas que não estão assentadas na ciência tradicional e sua noção de verdade absoluta. As análises relativas aos paradigmas outros estão vinculadas às diversas formas de pensamento, mas, na maior parte dos casos, questionam o colonialismo e a modernidade (MIGNOLO, Walter. "Prefacio a la edición castellana. Un paradigma otro: colonialidad global, pensamiento fronterizo y cosmopolitismo crítico. In: Historias locales / diseños globales: colonialidad, conocimientos subalternos y pensamiento fronterizo. Madrid: Ediciones Akal. 2003. p.19-58).

${ }^{13}$ A autora desenvolveu sua pesquisa sobre as prática de atenção à saúde entre os profissionais da enfermagem no contexto dos Distritos Sanitários Especiais Indígenas, que prestavam atendimento aos Mundruku, na Região do Alto Rio Tapajós, no Pará.
} 
Desta forma, as relações de poder constituíam o processo de tomada de decisões em relações as práticas de tratamento e cura de doença, invertendo o sentido do atendimento diferenciado enquanto sistema de produção do respeito à diversidade de entendimento saúde/doença entre os povos originários (SILVA 2010: 2).

Entendemos a partir do trabalho de Silva (2010) que mesmo permeado de conflitos, ainda devido a visão hierárquica e colonialista que pensa as relações com os indígenas de forma tutelar, o Sistema de Saúde Indígena é importante nas práticas relacionadas a saúde dos povos originários ${ }^{14}$, visto que muitas doenças que acometem os mesmos foram adquiridas a partir do contanto com os não índios, portanto, demanda interlocução entre as duas práticas, como consequência dos processos de ressignificações inerentes ao devir índio. ${ }^{15}$

Para o sentido contemporâneo de cultura, o homem é o resultado histórico de um regime de subjetivação específico que conjuga a admissão de significados e a ressignificação complexa desses valores em uma estrutura aberta, voltada para a diferença e a desconstrução. Admitindo ao mesmo tempo a conformação de determinados aspectos da vida simbólica e a estruturação linguística com potencial para os cruzamentos de significados, atravessamentos e linhas de fuga, capazes de promover escalonamentos, o devir corresponderia ao processo de segmentação das linhas de fuga, expressas nas multiplicidades do rizoma, o devir é um processo de desterritorialização e reterritorialização para determinado significante/sujeito, processo que traça consequentemente novas linhas de fuga e se desenvolve em tramas, capilaridades. A mudança se tornaria então, uma categoria cíclica, diacrônica (DELEUZE \& GUATARRI 1995:18).

Desta forma o conceito de rizoma nos auxilia no entendimento destas conexões conflituosas e inesperadas, que geram arranjos entre uma prática e outra. Quando a enfermeira ${ }^{16}$ mediante "um menino a beira da morte precisa aguardar a chegada do pajé" (SILVA, 2010:2) ou problemas com a cama do hospital "índio não gosta de

\footnotetext{
${ }^{14}$ Este trabalho foi resultado de uma pesquisa entre os Munduruku.

${ }^{15}$ Os povos originários sempre foram agentes, sujeitos da sua própria história, a relação com o outro sempre existiu, e mais que isso, esta relação sempre produziu subjetividade (Mano: 2015, p. 57 -72).

${ }^{16}$ A presença (figura) do médico no contexto da saúde indígena no Brasil não é muito constante, devido à falta de investimentos nesta área, assim as práticas médicas ficam sob responsabilidade de enfermeiras e enfermeiros e agentes de saúde.
} 
dormir em cama, acorda todo dolorido" (SILVA 2010: 225) nos mostra que estes elementos que percorrem os campos de significados de ambas as práticas, em relação às técnicas adquiridas pela medicina e formas diferentes de conceber o corpo, a doença e saúde caminham para a ressignificação tanto pelos povos originários (xamã) quanto pela medicina no contexto da saúde indígena (médico).

Já na abordagem da etnofarmacologia ${ }^{17}$ nos deparamos com um ramo do conhecimento científico que visa "promover a exploração científica interdisciplinar dos agentes biologicamente ativos, tradicionalmente empregados ou observados pelo homem" (Holmes-Tedt e Bruhn, apud, Silveira 2012: 41). Este ramo de atuação científica compreende a associação de pesquisadores das "ciências farmacêuticas" (botânica, fotoquímica, bioquímica, genética, toxicologia, etc.), agrônomos e antropólogos" (Davis, apud, Silveira 2012: 41). Esta disciplina associada ao pensamento científico foi instituída enquanto tal "tendo como objeto o estudo do mecanismo medicamento-doença nas chamadas sociedades "tradicionais" (Elisabetsky e Souza, apud, Silveira 2012: 41). O levantamento etnofarmacológico, no campo da farmacognosia, é direcionado para a obtenção de dados que permitam a construção de suposições passíveis de testes em laboratórios. Este processo é denominado pelos farmacólogos de "validação científica" dos conhecimentos tradicionais (Silveira 2012: 41):

[..]“dizem que um santo remédio para crise de asmas é tomar o chá de raízes de cicraninha? $\mathrm{H}^{1}=$ o remédio é útil no manejo da crise asmática; $\mathrm{H}^{2}=0$ remédio não tem essa utilidade. Essas hipóteses deverão ser testadas com todos os controles e rigores que qualquer ciência séria exige" (Elisabetsky e Souza, apud, Silveira 2012: 41).

Como consequência, as distintas perspectivas nativas de interlocução entre o pensamento científico e os conhecimentos tradicionais "indígenas e ribeirinhos" abrangem um encadeamento de "práticas de tradução de um mundo no outro (e de um objeto no outro)" (Silveira 2012: 349):

\footnotetext{
${ }^{17}$ Em eu livro "As Redes Sociotécnicas na Amâzonia, tradução de saberes no campo da biodiversidade" SILVEIRA (2012) faz uma abordagem sobre "a relação dos saberes na área da biodiversidade", mostrando que esta relação faz parte do contato entre ocidentais, índios e ribeirinhos na Amazônia. Uma relação assinalada pela violência e pela desapropriação de conhecimentos, mas que também deu origem a uma sucessão de ações de colaboração "intercientífica".
} 
Isso ocorre, por exemplo, na tradução das formas indígenas de conhecimento colocadas em prática pelos índios do Alto Rio Negro nos espaços da roça e da floresta para a linguagem conceitual da ecologia e da agronomia; ou na tradução dos sintomas ou modos de uso ribeirinho das plantas medicinais para a linguagem conceitual e teórica da farmacologia. Por outro lado, vimos como os índios e ribeirinhos traduzem e agenciam a relação com os pesquisadores e com as ciências ocidentais na forma de iniciativas como a farmacinha e a feirinha (Silveira 2012: 349).

Ao transpor essas práticas que permitem o tratamento, cura de doença entre as culturas dos povos originários e a sociedade ocidental percebemos que ambas podem ser vistas como parte de um rizoma, porque imbricam-se nele elementos de diferentes culturas em contato, adquirindo no contexto urbano essa característica polimorfa, apresentando-se de várias forma; ora essas práticas se encontram ora se distanciam.

\section{CONCLUSÃO}

Faça a linha e nunca o ponto! A velocidade transforma o ponto em linha! Seja rápido, mesmo parado! Linha de chance, jogo de cintura, linha de fuga. Nunca suscite um General em você! Nunca ideias justas, justo uma ideia -Gilles Deleuze \& Félix Guattari

Neste artigo a doença e a cura se desenvolvem em torno da relação entre dois modelos de conhecimento, denominados conhecimento tradicional e medicina ocidental, a partir da abordagem do xamã e do médico. Os conceitos de saúde e doença, assim como as interpretações a respeito destas técnicas, constitui-se em um terreno de intensa conciliação de significados e práticas.

O processo saúde-doença-cura se configura como uma ação dinâmica, complexa e multidimensional por englobar dimensões biológicas, psicológicas, socioculturais, econômicas, ambientais, políticas, etc. Desta forma, podemos identificar uma complexa relação quando se trata de saúde, doença e cura de um indivíduo, de um grupo social ou de sociedades. A partir das duas construções cosmológicas apresentadas ao longo do trabalho (xamanismo e medicina ocidental) podemos apreender sentidos diferentes relacionados à saúde, doença, tratamento e cura.

O xamanismo e a medicina ocidental se apresentam como técnicas diferentes, pois cada um foi construído historicamente a sua maneira, conforme aspectos já mencionados (razão, tradição, valores), o que faz da interlocução entre estes dois 
conceitos uma prática nem sempre favorável aos sentidos e significados inerentes a cada um.

\section{REFERÊNCIAS}

BRASIL. 1988. Constituição da República Federativa do Brasil.

BRASIL. Ministério da Saúde. 2002. Fundação Nacional de Saúde. Política Nacional de Atenção à saúde dos povos indígenas. $2^{\mathrm{a}}$ ed. Brasília.

BRASIL. Ministério da Saúde. 2006. Fundação Nacional de Saúde. $4^{a}$ Conferência Nacional de Saúde Indígena, Rio Quente-GO.

BRASIL, Ministério da Saúde. 2009. Dicionário da Educação Profissional em Saúde. Fundação Oswaldo Cruz. Escola Politécnica de Saúde Joaquim Venâncio, Rio de Janeiro.

BARROS, José Augusto. 2002. "Pensando o processo saúde doença: a que responde o modelo biomédico.” In: Saúde Soc.[online]. v.11, n.1, p.67-84.

BEATO, Claudio. 1994. "Práticas de Glosa e Anamnese.” In: Revista de saúde coletiva. Physis [online]. 1994, vol.4, n.1, pp.41-56.

CAPRA, Fritjof. 1982. O ponto de mutação. A ciência, a Sociedade e a Cultura emergente. $15^{\mathrm{a}}$ ed. Tradução de: Álvaro Cabral. São Paulo, Editora Cultrix.

CUNHA, Manuela. 1998. Cultura com aspas: Pontos de vistas sobre a floresta amazônica: Xamanismo e Tradução. $2^{\mathrm{a}}$ ed. São Paulo, Cosac Naify.

VIVEIROS DE CASTRO. Eduardo. 2003. A inconstância da alma selvagem e outros ensaios de Antropologia. $1^{\text {a }}$ ed. São Paulo, Cosac \& Naif.

2002. “O nativo relativo”. In: Mana, v. 2, n. 2, p. 113-148.

DE BARROS, Manoel. 2015. Meu quintal é maior que o mundo. $1^{\mathrm{a}}$. ed. Rio de Janeiro, Alfaguara.

DELlEUZE, Guilles; GUATARRI, Félix. 1995. Mil Platôs - capitalismo $e$ esquizofrenia. $2^{a}$ ed. vol 1. Tradução de Ana Lúcia de Oliveira, Aurélio Guerra Neto e Celia Pinto Costa. São Paulo, Editora 34.

FOUCAULT, Michel. 1979. Microfísica do poder. $1^{a}$ ed. Organização e Tradução de Roberto Machado. Rio de Janeiro, Edições Graal.

2010. A ordem do discurso. $20^{\mathrm{a}}$ ed. Tradução de Laura Fraga de Almeida Sampaio. São Paulo, Edições Loyola. 
GARNELO, Luiza; PONTES, Ana Lúcia. (orgs). 2012. Saúde Indígena: uma introdução ao tema. Brasília, Editora MEC-SECADI, p. 17 - 59.

GEERTZ, Clifford. 1989. A interpretação das culturas. $1^{\mathrm{a}}$ ed. Tradução de: The interpretation of cultures. Rio de janeiro, Editora LTC.

KRIPPNER, Stanley. 2007. "Os primeiros curadores da humanidade: abordagens psicológicas e psiquiátricas sobre os xamãs e o xamanismo." Archives of Clinical Psychiatry, São Paulo. Rev. Psiq. Clín. 34, supl 1; p. 17-24.

JUDD et al. 2009. Sistemática vegetal um enfoque filogenético. $3^{\mathrm{a}}$ ed. Tradução de: André Olmos Simões, Rodrigo B. Singer, Rosana Farias Singer e Tatiana Teixeira de Souza Chies. Porto Alegre, Artmed.

LAGDON, Esther. 1996. "Xamanismo e representação entre os Kaxinawá." In: Xamanismo no Brasil: novas perspectivas. Florianópolis, Ed. da UFSC, p. 197-232.

COSTA, Lucia Helena. COELHO, Edméia. 2010. "Enfermagem e sexualidade: revisão integrativa de artigos publicados na Revista Latino - Americana de Enfermagem e na Revista Brasileira de Enfermagem." Rev. Latino-Am. Enfermagem [Internet]. maio-jun 2011, 19(3):[10 telas]. In: http://www.scielo.br/pdf/rlae/v18n3/pt_23 (Acessado dia 04 de dezembro de 2018).

LATOUR, Bruno. 1994. Jamais fomos modernos. Tradução de: Carlos Irineu da Costa. São Paulo, Editora 34.

LÉVI-STRAUSS, Claude. 1975. Antropologia Estrutural. 4a ed. Tradução de: Cham Samuel Katz e Eginardo Pires. Rio de Janeiro, Tempo Brasileiro.

Lei Federal No. 8.080, 1990.

Lei Federal No 8.142, 1990.

MANO, Marcel. 2015. “(Des) encontros culturais: um esboço parcial da história do contato dos Kayapó meridionais”. In: FERREIRA FILHO, Aurelino (Org.). Índios do triangulo mineiro: história, arqueologia, fontes e patrimônio, pesquisas e perspectivas. Uberlândia, EDUFU. p.57 - 72.

MARTINS, Roberto et al. 1997. Contágio: história da prevenção das doenças transmissíveis. São Paulo, Editora Moderna.

MIGNOLO, Walter. 2003."Prefacio a la edición castellana. Un paradigma otro: colonialidad global, pensamiento fronterizo y cosmopolitismo crítico. In: Historias locales / diseños globales: colonialidad, conocimientos subalternos y pensamiento fronterizo. Madrid, Ediciones Akal p.19-58.

SEEGER, Anthony; DA MATTA, Roberto; VIVEIROS DE CASTRO, Eduardo. 1979. "A Construção da Pessoa nas Sociedades Indígenas Brasileiras." In: Boletim do Museu Nacional. Rio de Janeiro, n. 32, p. 1-12. 
SILVA, Cristina. 2010. Cotidiano, saúde e política: uma etnografia dos profissionais da saúde indígena. Tese de Doutorado em Antropologia, Universidade de Brasília.

SILVEIRA, Diego. 2012. As Redes Sociotécnicas na Amâzonia, tradução de saberes no campo da biodiversidade. Rio de Janeiro, Editora: Multifoco.

SOCIEDADE BRASILEIRA DE FARMACOGNOSIA. 2009. O que é farmacognosia? In: http://www.sbfgnosia.org.br/farmacognosia.html (Acessado dia 9 de dezembro de 2018). 